\title{
Microalgae of Odisha Coast as a Potential Source for Biodiesel Production
}

\author{
Jayashree Jena ${ }^{1, *}$, Manoranjan Nayak ${ }^{1}$, Himansu Sekhar Panda ${ }^{1}$, Nilotpala Pradhan ${ }^{1}$, \\ Chandragiri Sarika ${ }^{2}$, Prasanna Ku. Panda ${ }^{1}$, Bhamidipati V. S. K Rao ${ }^{2}$, Rachapudi B. N. Prasad ${ }^{2}$, \\ Lala Behari Sukla ${ }^{1}$
}

${ }^{1}$ Bioresources Engineering Department, CSIR-Institute of Minerals and Materials Technology Bhubaneswar, Odisha, 751013, India ${ }^{2}$ CSIR-Indian Institute of Chemical Technology, Hyderabad, 500607, A.P, India

\begin{abstract}
In recent years microalgae have been proved as the potential source for biodiesel production due to high oil content. In the present study three brackish water microalgal strains (Chlorococcum sp., Chlorella sp. and Scenedesmus sp.) of Odisha coast were screened for the suitability for biodiesel production. Among all, Scenedesmus sp. seems to be the best one for high lipid productivity $(24.66 \mathrm{mg} / \mathrm{L}$ day) with high biomass yield of $0.9 \mathrm{~g} / \mathrm{L}$ at stationary phase. Also the Scenedesmus sp. possesses the most adequate fatty acid profile. The present study suggested that Scenedesmus sp. is appropriate for biodiesel production for its high lipid content; this strain was selected for higher scale studies.
\end{abstract}

Keywords Microalgae, Scenedesmus sp., Fatty Acid, Biodiesel

\section{Introduction}

Fuels represent around $70 \%$ of the total global energy requirements, particularly in transportation, manufacturing and domestic heating[1]. It is expected that there will be a $60 \%$ increase in global energy requirement by 2030 over its present consumption level leading to more environmental damage. Out of this increase, $45 \%$ is accounted by developing countries like India and China as they are new growing economies. Search for clean and renewable energy sources ranks as one of the most daunting challenges for mankind which is intimately linked with economic development, global stability and quality of life[2]. Continued use of fossil fuel in the transport sector would not only become unsustainable but also contribute significantly to global warming due to carbon dioxide $\left(\mathrm{CO}_{2}\right)$ emissions. European Union government established $\mathrm{CO}_{2}$ emission reduction targets in the range of $10-20 \%$ by $2020[3,4]$. Thus there is significant need for an alternative fuel that is renewable and has lower carbon foot print or is carbon neutral.

Biofuel offers new opportunities to diversify fuel supply sources for long term replacement of fossil fuels, along with carbon sequestration. This would reduce GHG emissions, enhance the decarbonisation of transportation fuels and increase the security of energy supply[1]. The common biofuels are biodiesel and bioethanol[5], gaining importance as they provides environmental benefits by reducing harmful

* Corresponding author:

jayashree_biotech@yahoo.com (Jayashree Jena)

Published online at http://journal.sapub.org/env

Copyright (C) 2012 Scientific \& Academic Publishing. All Rights Reserved emissions of carbon monoxide, SOx, NOx, hydrocarbons and particulate matter[2,6-8].

First generation biofuels which have now attained economic levels of production, have been mainly extracted from food and oil crops including rapeseed oil, sugarcane, sugar beet, and maize as well as vegetable oils and animal fats using conventional technology[9]. But these have negative impact on global food markets and on food security [10]. To overcome this controversy second generation biofuels evolve where fuels are produced from the whole plant matter of dedicated energy crops or agricultural residues, forest harvesting residues or wood processing waste[11]. However, the technology for conversion in the most part has not reached the scales of significant commercial exploitation [12]. In contrast, transition to third generation biodiesel, which are derived from microalgae, have emerged as one of the most promising alternative sources of lipid for use in biodiesel production[13]. Microalgae are prokaryotic or eukaryotic sun light driven cell factories that coverts $\mathrm{CO}_{2}$ and water to potential biofuel, foods, feeds and high value bioactive[5]. They are superior to traditional oleaginous crops due to higher photosynthetic efficiency, faster growth rate, higher biomass productivities, highest $\mathrm{CO}_{2}$ fixation and $\mathrm{O}_{2}$ production rate. Also it can be grown in variable climates, non arable land including marginal areas unsuitable for agricultural purpose, no seasonal production, thrive in non portable water, use less water and do not compete with food crop culture[2,14,5,15].

The average yield of microalgal biodiesel production is 10 to 20 times higher and requires 49-132 times less land area than the other oleaginous seeds[9]. The content of lipid, carbohydrate and proteins varies from species to species. 
Most common algae like Chlorella, Crypthecodinium, Cylindrotheca, Dunaliella, Isochrysis, Nannochloris, Nannochloropsis, Neochloris, Nitzschia, Phaeodactylum, Porphyridium, Schizochytrium, Tetraselmis, Botryococcus braunii and Scenedesmus have oil levels between 20 and 50\% but higher productivities can be reached[1,16-20]. Under adverse growth conditions such as nitrogen limitation, low temperature, high light intensity, high salt concentration and high iron concentration the lipid content in some of microalgae increased[21,19]. This was due to alteration in their lipid biosynthesis pathways towards the formation and accumulation of neutral lipids. Lipid accumulation was up to $80 \%$ of dry cell weight (DCW) and mainly in the form of triacylglycerol due to the shift in metabolism from membrane lipid synthesis to the storage of neutral lipids TAG [22-24]. Growth of Chlorella vulgaris in low nitrogen and iron supplemented medium produced lipid up to $40 \%$ and $56.6 \%$ respectively[25,16]. Saturated and unsaturated fatty acids like Palmitic acid (C16:0), stearic acid (C18:0), oleic acid (C18:1), linoleic acid (C18:2), and linolenic acid (C18:3) are common fatty acids for biodiesel production. In particular, these fatty acids are strong candidates for improving the quality of biodiesel[26].

$\mathrm{CO}_{2}$ fixing efficiency of algae is important for removing power plant gases from emissions. Thus it is a potential candidate for green house gas reduction combined with higher microalgal biomass productivity and consequently higher biodiesel production[2]. In terms of amount, carbon is the dominant nutrient $(45-50 \%$ of the dry algal mass); so, theoretically, $1.65-1.83 \mathrm{gCO}_{2}$ is needed for the biosynthesis of $1 \mathrm{~g}(\mathrm{DW})$ of algal biomass[27].

Odisha state is located on the east coast region of India and has a large coastal plain called "Hexadeltaic region". It stretches along the coast of the Bay of Bengal. Odisha has a large brackish aquatic systems. A number of microalgal strains prefer brackish conditions because of its nutritional composition of the aquatic system and the warmer temperatures[28,29]. If this long coast could be used for microalgal biodiesel production using the locally isolated strains then it may prove to be advantageous as they are already adapted and dominant strains.

In view of this, the present study was carried out to screen the potential microalgae of brackish water habitats of Odisha, India. The microalgal strains were tested for biodiesel production ability, based on their biomass yield, oil productivity and fatty acid profile.

\section{Materials and Methods}

\subsection{Microalgae Sample Collection and Isolation}

Microalgae rich samples were collected randomly at different sites of Bahuda river mouth (India) and its adjoining area during January 2010 (temperature $25-28^{\circ} \mathrm{C}$ and $\mathrm{pH}$ ranges from 6.5-8.5). Bahuda River which originates in Gajapati district of the Eastern Ghat region of Odisha joins
Bay of Bengal in Odisha-Andhra Pradesh border, spanning a length of $1250 \mathrm{~km}^{2}$ catchments area. The tidal effect and anthropogenic activity made this habitat suitable for the growth of various group of algae in and around this region.

Samples were cultured in modified Bold Basal medium (BBM) and subsequently purified by serial dilution. Pure culture obtained from single cell was established in both agar slant and liquid of BBM. All the strains were deposited in the repository of Institute of Minerals and Materials Technology (CSIR), Bhubaneswar, Odisha, India.

The microalgal strains had been characterized microscopically by comparing with those reported species (http:// www.algalweb.net). Purity of the culture was ensured by repeated plating and by regular observation under microscope.

\subsection{Culture Conditions}

All the cultures were cultivated in modified Bold Basal medium[30] which was composed of (mg/L): $\mathrm{KH}_{2} \mathrm{PO}_{4}(175)$, $\mathrm{CaCl}_{2} \cdot 2 \mathrm{H}_{2} \mathrm{O}(25), \mathrm{MgSO}_{4} \cdot 7 \mathrm{H}_{2} \mathrm{O}(75), \mathrm{NaNO}_{3}(250), \mathrm{K}_{2} \mathrm{HPO}_{4}$ (75), $\mathrm{NaCl}(250), \mathrm{Na}_{2}$ EDTA (50), $\mathrm{KOH}(31), \mathrm{FeSO}_{4} \cdot 7 \mathrm{H}_{2} \mathrm{O}$ (4.98), $\mathrm{H}_{2} \mathrm{SO}_{4}$ (conc.) $(1 \mu \mathrm{l}), \mathrm{H}_{3} \mathrm{BO}_{3}(11), \mathrm{MnCl}_{2} .4 \mathrm{H}_{2} \mathrm{O}$ (1.81), $\mathrm{ZnSO}_{4} .7 \mathrm{H}_{2} \mathrm{O}(0.222), \mathrm{NaMoO}_{4} .5 \mathrm{H}_{2} \mathrm{O}(0.39), \mathrm{CuSO}_{4} .5 \mathrm{H}_{2} \mathrm{O}$ (0.079), $\quad \mathrm{Co}\left(\mathrm{NO}_{3}\right)_{2} \cdot 6 \mathrm{H}_{2} \mathrm{O} \quad(0.0494), \quad \mathrm{NaOH}(0.01 \mathrm{~N}) . \quad \mathrm{pH}$ maintained at 6.8 by passing saturated $\mathrm{CO}_{2}$ at every $24 \mathrm{hrs}$ interval. The cultures were maintained in an automated culture laboratory with temperature of $25 \pm 2^{\circ} \mathrm{C}$ under a $16: 8 \mathrm{~h}$ photoperiod with a light intensity of 3500 lux provided by cool white fluorescent tubes. The cultures were agitated at 126rpm in an orbitar shaker to avoid sticking.

For seed culture, $100 \mathrm{ml}$ of basal medium taken in a 250 $\mathrm{ml}$ Erlenmeyer flask was inoculated and incubated till exponetial growth phase was reached under continuous illumination. Then the culture was transferred to 1 lit flask containing $500 \mathrm{ml}$ same media. Seed culture always maintained in logarithmic phase and the microalgal cells were pelleted by centrifugation at $5000 \mathrm{rpm}$ for $15 \mathrm{mins}$ and after resuspension in fresh medium were used as inoculum for further experiments.

Growth (Cell density) of cultures was monitored by measuring the optical density at $750 \mathrm{~nm}$ with help of UV-Vis spectrophotometer (Cecil UV-Vis spectrophotometer). Dry cell weight $(\mathrm{DCW})$ of microalgal culture was determined using a calibration curve of known optical density and respective dry weights were determined gravimetrically after drying the algal cells at $60^{\circ} \mathrm{C}$ ( Table 1). Direct microscopic count was performed with an improved Neubauer hemocytometer and a Nikon Epi-fluorescence microscope. $\mathrm{pH}$ of the microalgal culture measured with the help of Systronic 362 $\mathrm{pH}$ meter.

Lipid Extraction was done using Chloroform: Methanol $(2: 1 \mathrm{v} / \mathrm{v})$ using modified Bligh \&Dyer method[31]. Organic phase containing lipid was vaccum dried. The lipid weight was calculated gravimetrically by subtracting original weight of container from final weight and expressed as $\%$ of DCW. 


\subsection{Kinetic and Yield Parameters}

The specific growth rate $(\mu, /$ day) was measured using the equation:

$$
\mu=\ln \left(\mathrm{W}_{\mathrm{f}} / \mathrm{W}_{0}\right) / \Delta \mathrm{t}
$$

Where, $\mathrm{W}_{\mathrm{f}}$ and $\mathrm{W}_{0}$ were the biomass concentration at the end and at the beginning of a batch run, respectively. $\Delta t$ was the cultivation time in days .

The yield of the microalgae lipids, Y (\%) was calculated using the equation:

$$
\mathrm{Y}=\mathrm{W}_{\mathrm{L}(\mathrm{g})}-\mathrm{W}_{\mathrm{I}(\mathrm{g})} / \mathrm{W}_{\mathrm{DA}(\mathrm{g})}
$$

Where $\mathrm{W}_{\mathrm{I}}$ and $\mathrm{W}_{\mathrm{L}}$ are the weight of the extraction flask before and after extracting the oil. $\mathrm{W}_{\mathrm{DA}}$ is the weight of the dry algae biomass.

The lipid productivity $v(\mathrm{mg} / \mathrm{L} /$ day) was calculated by using the equation:

$$
v=\mathrm{C}_{\mathrm{L}} / \mathrm{t}
$$

Where $\mathrm{C}_{\mathrm{L}}(\mathrm{mg} / \mathrm{L})$ is the concentration of lipid at the end of the batch run and $t$ is the duration of the cultivation.

\subsection{Analysis of Fatty Acid Composition}

Typical procedure for the preparation of fatty acid methyl esters:

For the Preparation of Fatty Acid Methyl Esters dried biomass $(0.25 \mathrm{~g})$ was taken in a $50 \mathrm{ml} \mathrm{RB}$ flask and to this 15 $\mathrm{ml}$ of $2 \%$ sulphuric acid in methanol solution was added. The contents were refluxed for $4.0 \mathrm{hrs}$. At the end of the reaction time the contents were diluted with water and the organic phase was extracted with ethyl acetate $(3 \times 25 \mathrm{ml})$. The ethyl acetate phase was thoroughly washed with water and dried over anhydrous sodium sulphate. Ethyl acetate was evaporated on a rotary evaporator to recover fatty acid methyl esters $(0.12 \mathrm{~g})$.

Gas Chromatographic Analysis of Fatty Acid Methyl Esters:

The fatty acid composition analysis of algal oil methyl esters was carried out on a gas chromatograph (Agilent 6890) equipped with a flame ionization detector (FID) on a split injector system. A fused silica capillary column (DB-225, $0.25 \mu \mathrm{m}, 30 \mathrm{~m} \mathrm{X} 0.32 \mathrm{~mm}$ id) was used for the analysis. Oven temperature was programmed from $170^{\circ} \mathrm{C}$ to $225^{\circ} \mathrm{C}$ at $1{ }^{\circ} \mathrm{C} / \mathrm{min}$. The injector and detector temperatures were held at 250 and $270^{\circ} \mathrm{C}$ respectively. Nitrogen was used as carrier gas at a flow rate of $1 \mathrm{ml} / \mathrm{min}$. The area percentages were recorded with Agilent chemstation data processing system.

\section{Results and Discussion}

\subsection{Growth of Microalgae at Shake Flask Study}

Growth parameters and lipid accumulation characteristics of some microalgal species were determined in order to screen them for large scale oil production. Three microalgal species were screened for their kinetic growth and lipid production. The relationship between Dry cell weight (DCW) and Optical density (OD) was best described by a power regression with a $\mathrm{R}^{2}$ close to 1 within an OD range from $0.1-2.2$. Based on this relationship, all the OD values were converted to biomass $(\mathrm{g} / \mathrm{L})$ that shown in Table 1. All results presented in this paper are based on the average of the three replicates.

Table 1. Regression Equation for biomass dry cell weight vs. optical Density

\begin{tabular}{|c|c|}
\hline Name of the strain & Regression equation of the cell density \\
\hline Chlorococcum $\mathrm{sp}$. & Biomass $=$ O.D $\times 5458\left(\mathrm{R}^{2}=0.9922\right)$ \\
\hline Chlorella $\mathrm{sp}$. & Biomass $=$ O.D $\times 4141\left(\mathrm{R}^{2}=0.9933\right)$ \\
\hline Scenedesmus $\mathrm{sp}$. & Biomass $=$ O.D $\times 4379\left(\mathrm{R}^{2}=0.9976\right)$ \\
\hline
\end{tabular}

The time-course of growth of all three microalgae strain under batch mode is presented in Fig 1. Cell number of the organisms increased steadily with a lag of 2days followed by the logarithmic phase for 3 days and attained the stationary phase at about 7 days. After 9 day of cultivation, average biomass growth was in range of $0.9-1.1 \mathrm{~g} / \mathrm{L}$ and respective productivities of 112,104,102 mg/L/day for Chlorococcum sp., Chlorella sp., Scenedesmus sp.

The specific growth rate $(\mu)$ was calculated from the biomass concentrations at the end and at the beginning of the cultivation time as per equation 1 shown in Table 2 .

The $\mathrm{pH}$ during the growth of three microalgae increased from 6.8 (initial) to 11.5 (final)(Fig.2). This may be due to utilization of carbon dioxide which leads to accumulation of free $\mathrm{OH}^{-}$ions. Though the culture $\mathrm{pH}$ increased, algae grew well without obvious inhibition between the $\mathrm{pH}$ ranges 7 to 9 . Similarly, Dayananda et al. reported that culture $\mathrm{pH}$ had no significant effects on the biomass yield and hydrocarbons production of B. braunii, when it ranged from 6.0 to $8.5[20]$.

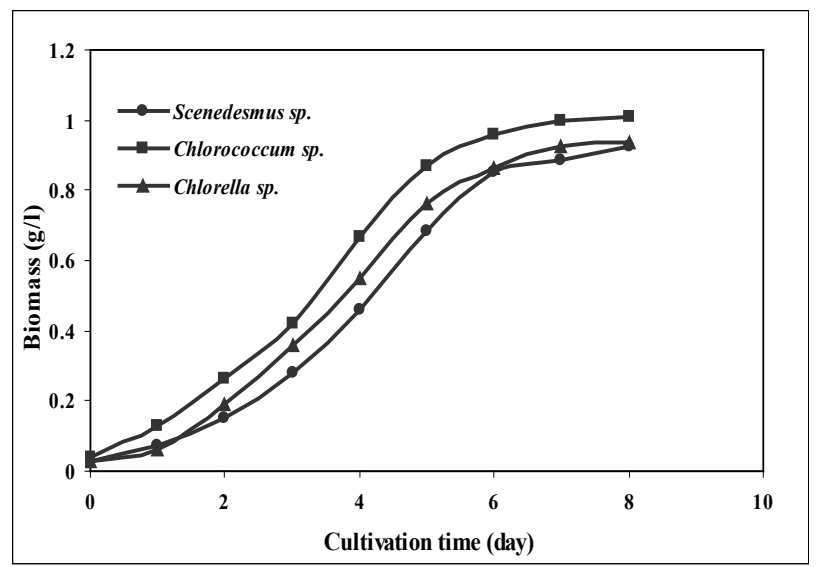

Figure 1. Growth study of microalgal strains

Table 2. Specific growth rate and lipid productivity of microalgal strains

\begin{tabular}{|c|c|c|c|c|}
\hline Sl. No. & Name of the strain & Specific growth rate $\mu$, day & Lipid Content(mg/l) & Total lipid productivityv (mg/L/day) \\
\hline 1 & Chlorococcum sp. & 0.35 & 112 & 12.44 \\
\hline 2 & Chlorella sp. & 0.38 & 145 & 16.11 \\
\hline 3 & Scenedesmus sp. & 0.38 & 222 & 24.66 \\
\hline
\end{tabular}




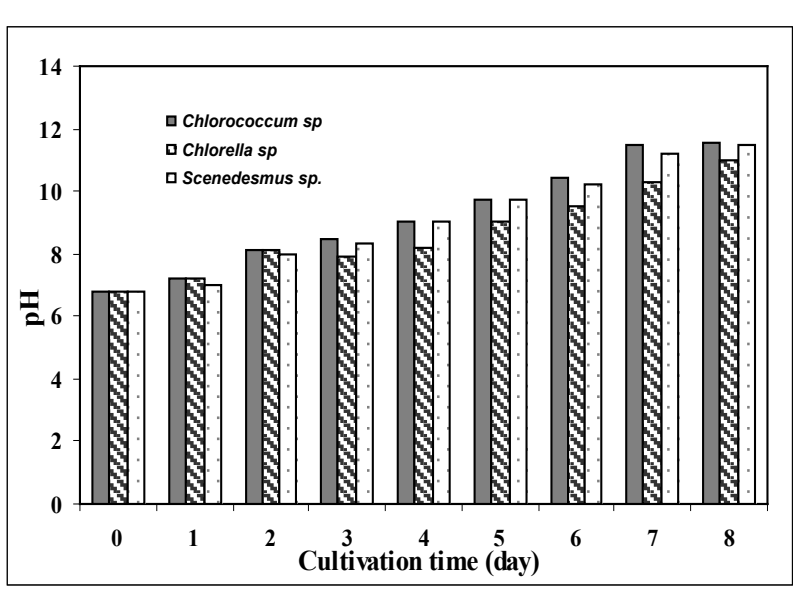

Figure 2. pH change during microalgal growth

\subsection{Lipid Productivity of Microalgae}

Percentage of lipid content at stationary phase i.e. 9days was measured for each strain. Results showed that all species had almost comparable growth rates, but Scenedesmus sp. showed highest lipid content of about $24 \%$ at the early stationary phase (Table 2, Fig 3). Accumulation of lipid though started at the early phase of growth but maximum accumulation was observed at the stationary phase. Accumulation of lipids as storage products when growth becomes limited may be reason behind this[32].

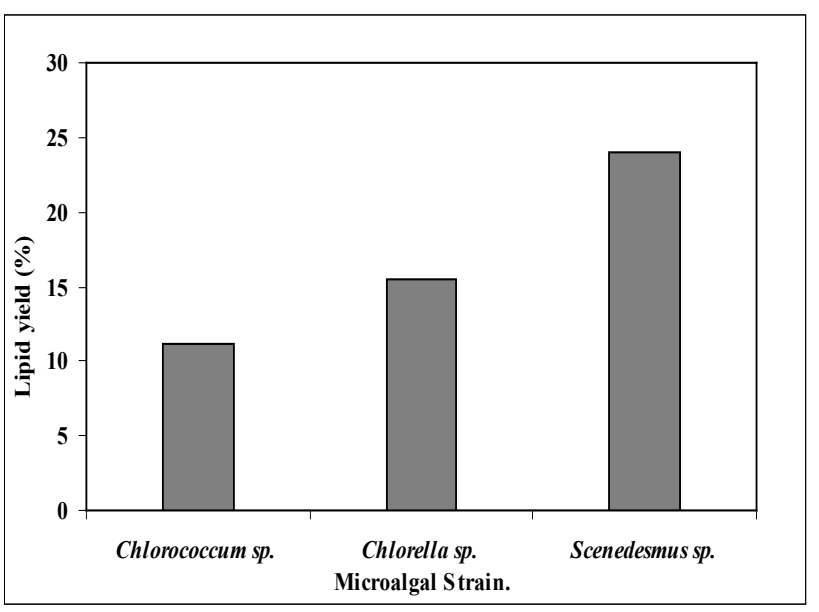

Figure 3. Total lipid content of microalgal strains

\subsection{Fatty Acid Composition of Total Lipids}

The fatty acid compositions of the three brackish water microalgal strain at stationary phase was determined (Table 3). Fatty acid compositions of microalgae differ from strain to strain. All microalgal lipids were mainly composed of unsaturated fatty acids (63-80\%) and a significant percentage (19.5-30.3 \%) of Palmitic acid (C16:0) was also present, which were the dominant saturated fatty acids in all microalgae. Among unsaturated fatty acids, special attention should be given to the linolenic (C18:3) and polyunsaturated fatty acids having four or more than four double bond content[2]. EN 14214 specifies a limit of 12 and $1 \%$ for linolenic acid and the fatty acid double bond respectively for biodiesel production[33]. From Table 3, it can be seen that the oil extracted from Scenedesmus sp. had 9.2\% linolenic acid and unsaturation $\geq 4$ within the specification with $63.5 \%$ of total unsaturated fatty acid. Besides this, the microalgae contains high amount of palmitic acid (16:0, 30.3\%). Among the unsaturated fatty acid, PUFA was high $(36.8 \%)$ represented by lenoleic acid (C18:2, 21.1\%) and oleic acid (18:1, 17.5\%). Other long chain PUFA are present in small amount. These properties make the strain suitable for biodiesel production.

Table 3. Fatty acid composition (\% of total fatty acids) of microalgal strains at stationary phase

\begin{tabular}{|c|c|c|c|}
\hline Fatty acid & Chlorococcum sp. & Chlorella sp. & Scenesdesmus sp. \\
\hline $12: 0$ & - & 0.3 & - \\
\hline $14: 0$ & - & 0.9 & 0.7 \\
\hline $15: 0$ & - & 0.3 & 0.3 \\
\hline $16: 0$ & 19.5 & 24.5 & 30.3 \\
\hline $16: 1$ & 6.2 & 4.9 & 6.5 \\
\hline $16: 2$ & 7.5 & 1.3 & 5.7 \\
\hline $16: 3$ & 2.2 & - & - \\
\hline $16: 4$ & 12.6 & - & - \\
\hline $17: 0$ & - & 2.1 & 2.6 \\
\hline $17: 1$ & 1.1 & 10.0 & 2.7 \\
\hline 18:0 & 0.5 & 2.5 & 1.2 \\
\hline $18: 1$ & 12.8 & 15.1 & 17.5 \\
\hline $18: 2$ & 13.7 & 5.7 & 21.1 \\
\hline $18: 3$ & 20.6 & 26.3 & 9.2 \\
\hline $18: 4$ & 2.5 & - & - \\
\hline $20: 0$ & 0.2 & 0.4 & 0.1 \\
\hline $20: 1$ & - & 00.4 & - \\
\hline $20: 2$ & 0.2 & 0.3 & 0.3 \\
\hline $20: 3$ & 0.2 & 0.3 & 0.1 \\
\hline $20: 4$ & - & - & - \\
\hline $20: 5$ & 0.1 & 1.1 & 0.8 \\
\hline $21: 0$ & - & 1.1 & - \\
\hline 22:0 & 0.1 & 1.1 & 0.6 \\
\hline $22: 1$ & - & 0.6 & - \\
\hline $24: 0$ & - & 0.8 & 0.3 \\
\hline $\begin{array}{l}\text { Saturated } \\
\text { fatty acid }\end{array}$ & 20.3 & 34.0 & 36.5 \\
\hline $\begin{array}{l}\text { Unsaturated } \\
\text { fatty acid }\end{array}$ & 79.7 & 66.0 & 63.5 \\
\hline
\end{tabular}

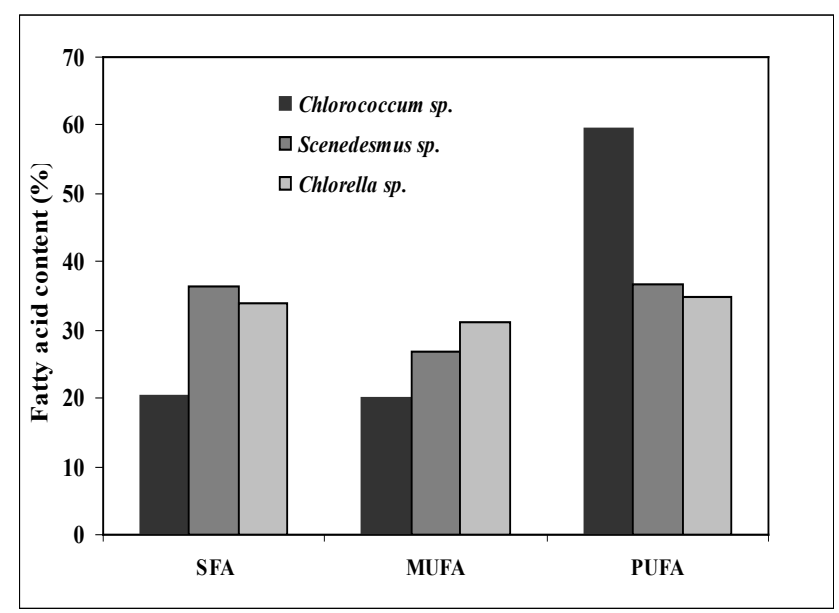

Figure 4. Comparison of Fatty acid

In Chlorococcum sp., the total saturated and unsatured fatty acids were 20.3 and $79.7 \%$ respectively (Table 3 ). This 
species had $\mathrm{C} 18: 3(20.6 \%), \mathrm{C} 16: 0(19.5 \%), \mathrm{C} 18: 2(13.7 \%)$ and $\mathrm{C} 18: 1(12.8 \%)$ as principal fatty acids. Total amount of PUFA in Chlorococcum species was nearly $60 \%$ of the total unsatured fatty acid (79.7\%) with C18:3(20.6\%), C18:2 (13.7\%), C16:4(12.6) as the major PUFA. High value of unsaturation, will be responsible for more iodine value (iodine value directly depends upon the degree of unsaturation), with high oxidation rate which creates long term storage problem.

The strain Chlorella sp, contained 34\% of saturated and $66 \%$ of unsaturated fatty acid (UFA) (Table 3). Higher amount of UFA was present among which PUFA content is $35 \%$. Among unsaturated fatty acids, linolenic acid was the most dominant fatty acid (26.3\%) Besides the PUFA, the strain also contain oleic acid (18:1, 15.1\%) and palmitic acid (16:0, $24.5 \%$ ) as principal fatty acids. Biodiesel from highly unsaturated sources oxidizes more rapidly than conventional diesel, resulting in forming insoluble sediments to interfere with engine performance. Therefore, the proper ratio of saturated and unsaturated fatty acid is very important to microalgae as a biodiesel feedstock. In brief, many parameters including lipid content, growth rate, fatty acid composition and cultivation conditions should be considered to identify the most promising microalgae species and to maximize oil yield per acre for biodiesel production[34].

Due to high lipid content and suitable fatty acid profile with acceptable biomass yield, the strain Scenedesmus sp. was further selected for upscaling purpose.

\section{Conclusions}

The present study deals with brackish water microalgal strains isolated from Odisha coast, eastern region of India for biodiesel production that are previously not been studied. The experimental result suggests that among the tested strains, Scenedesmus sp. was found to be the best candidate for biodiesel production due to high lipid content and high lipid productivity. Also the qualitative analysis of fatty acid show high value of palmitic acid along with maximum amount of unsaturated fatty acids. Due to the high value of PUFA i.e. C18:3, C18:2, C16:4 these studied strains could also be use in neutraceutical application.

Further, process control and optimization are worth studying to develop an economically feasible biodiesel production protocol.

\section{ACKNOWLEDGEMENTS}

The authors are thankful to the Department of Biotechnology (DBT) New Delhi, Govt. of India for their financial support and Prof. B.K. Mishra, Director, Institute of Minerals \& Materials Technology (CSIR) for providing laboratory facilities. The authors are thankful to Biswaranjan Das, Technical Assistant, CSIR-IMMT for technical support.

\section{REFERENCES}

[1] Mata, T.M., Martins, A.A., and Caetano, S.N., 2010, Microalgae for biodiesel production and other applications: A review. Renew. Sustain. Energy. Rev. 14: pp.217-232

[2] Gouveia, L. and Oliveira, A.C., 2009, Microalgae as a raw material for biofuel production. J. Ind. Microbiol. Biotechnol. 36: pp. 269-274

[3] IPCC Intergovernmental Panel on Climate Change 'AR4 Synthesis report'. www.ipcc.ch(2007)

[4] Stern, N., 2006, The Economics of Climate Change. HM Treasury, London

[5] Chisti, Y., 2007, Biodiesel from Microalgae. Biotechnol. Adv. 25: pp .294-306

[6] Al-Widyan, M.I. and Al-Shyoukh, A.O., 2002, Experimental evaluation of the transesterification of waste palm oil into biodiesel. Bioresour. Technol. 85: pp. 253-256

[7] Antolin, G., Tinaut F.V., Briceno Y., Castano, V., Perez, C. and Ramirez, A.I., 2002,Optimisation of biodiesel production by sunflower oil transesterification. Bioresour. Technol. 83: pp.111-114

[8] Lang, X., Dalai, A.K., Bakhshi, N.N, Reaney, M.J, and Hertz, P.B., 2001, Preparation and characterization of bio-diesels from various biooils. Bioresour. Technol. 8: pp.53-62

[9] FAO,2008, Biofuels -Prospects, Risks and Oppertunities. The state of food and agriculture. New York: Food and Agriculture Organization

[10] Brennan, L. and Owende, P., 2010, Biofuels from microalgae - a review of technologies for production, processing, and extractions of biofuels and co-products. Renew. Sustain. Energy Rev. 14: pp. 557-577

[11] Lim, S., and Teong, L.K., 2010, Recent trends, opportunities and challenges of biodiesel in Malaysia: an overview. Renew. Sustain. Energy Rev.14: pp. 938-954

[12] Demirbas, A., 2002, Diesel fuel from vegetable oil via transesterification and soap pyrolysis. Ener. Source. 24: pp. $835-841$

[13] Ahmad, A.L., Yasin Mat, N.H., Derek, C.J.C., and Lim, J.K., 2011, Microalgae as a sustainable energy source for biodiesel production: A review. Renew. Sustain. Energy Rev. 15: pp 584-593

[14] Campbell, C.J., 1997, The coming oil crisis. Multi-science Publishing Company and petroconsultants S.A, Essex, England

[15] Chisti, Y., 2008, Biodiesel from microalgae beats bioethanol. Trends in Biotechnol. 26: pp.126-131

[16] Illman, A.M., Scragg, A.H., and Shales, S.W., 2000, Increase in Chlorella strains calorific values when grown in low nitrogen medium. Enz. Microb. Technol. 27: pp.631-635

[17] Xiong, W., Li, X., Xiang, J., and Wu, Q., 2008, High-density fermentation of microalga Chlorella protothecoides in bioreactor for microbiodiesel production. Appl. Microbiol. Biotechnol. 78: pp.29-36

[18] Takagi, M., Watanabe, K., Yamaberi K., and Yoshida, T., 2000, Limited feeding of potassium nitrate for intracellular 
lipid and triglyceride accumulation of Nannochloris sp. UTEX LB1999. Appl. Microbiol. Biotechnol. 54: pp.112-11 7

[19] Li, Y., Horseman, M., Wang, B., Wu, N., and Lan, C.Q., 2008, Effects of nitrogen sources on cell growth and lipid accumulation of green alga Neochloris oleoabundans. Appl. Microbiol. Biotechnol. 81:pp.629-636

[20] Dayananda, C., Sarada, R., Kumar, V., and Ravishankar,G.A., 2007, Isolation,characterization of hydrocarbon producing green microalgae Botryococcus braunii from Indian freshwater bodies. Elec. J Biotechnol. 10: pp.78-91

[21] Hsieh, C.H., and Wu, W.T., 2009, Cultivation of microalgae for oil production with a cultivation strategy of urea limitation. Biores. Technol. 100: pp.3921-3926

[22] Hu, Q., Sommerfeld, M., Jarvis, E., Ghirardi, M., Posewitz, M., Seibert, M., and Darzins, A., 2008, Microalgal triacyglycerols as feedstocks for biofuel production: Perspectives and advances. Plant. J. 54: pp. 621-639

[23] Spolaore, P., Joannis-Cassan C., Duran, E., and Isambert, A., 2006, Commercial applications of Microalgae-review. J. Biosc. Bioeng. 101: pp. 87-96

[24] Tonon, T., Harvey, D., Larson, T.R., and Graham, I.A., 2002, Long chain polyunsaturated fatty acid production and partitioning to triacylglycerols in four microalgae. Phytochem. 61: pp.15-24

[25] Liu, Z.Y., Wang, G.C., and Zhou, B.C., 2008, Effect of iron on growth and lipid accumulation in Chlorella vulgaris. Biores. Technol. 99: pp. 717-4722

[26] Lee, S.J., Go, S., Jeong, G.T., and Kim, S.K, 2011, Oil Pro- duction from Five Marine Microalgae for the Production of Biodiesel. Biotechnol. Bioproc. Eng. 16: pp.561-566

[27] Doucha, J., Straka, F. and Livansky, K., 2005, Utilization of flue gas for cultivation of microalgae (Chlorella sp.) in an outdoor open thin-layer photobioreactor. J. Appl. Phycol. 17: pp.403-412

[28] Mutanda, T., Ramesh, D., Kartikeyan, S., Kumari, S., Anandraj, A. and Bux, F., 2011, Bioprospecting for hyper lipid producing microalgal strains for sustainable biofuel production. Biores. Technol. 102:pp.57-70

[29] Woelfel, J., Schumann, R., Adler, S., Hubener, T., and Karsten, U., 2007, Diatoms inhabiting a wind flat of the Baltic sea:species diversity and seasonal variations. Estuar. Coast shelf Sci. 75:pp.296-307

[30] Stein, J.R. (ed.), 1973, Handbook of Phycological Methods: Culture Methods and Growth Measurements. Cambridge University Press, pp 448

[31] Bligh, E.G. and Dyer, W.J., 1959, A rapid method of total lipid extraction and purification. Cann. J. Biochem. Phy. 37: pp. $911-917$

[32] Boussiba, S., Vonshak, A., Cohen, Z., Avissar, Y., and Richmond, A., 1987, Lipid and biomass production by the halotolerant microalga Nannochloropsis salina. Biomass 12:pp.37-47

[33] Europian standard EN14214, 2004,Automotive fuels-fatty acid methyl esters (FAME) for diesel engines,requirements and test methods

[34] Deng, X., Li, Y., and Fei, X., 2009, Microalgae: A promising feedstock for biodiesel. Afr. J. Microb. Res. 3: pp.1008-1014 